\title{
COVID-19, the Disease that Has Shined a Light on Health Equity
}

\author{
Joseph Keawe‘aimoku Kaholokula
}

Not even Hollywood could dream up a more fantastic plot for a movie.

A global plague causes economic turmoil. The United States, a superpower once envied by other nations, is now mocked because of an egomaniacal president. A third of its citizens are unemployed. People on the right and left of the political spectrum take to the streets in protest. Major US cities are set afire. Domestic supplants international terrorism as a national security concern.

This plot seems too unbelievable to be true. Yet, it is our reality.

The coronavirus disease 2019 (COVID-19) pandemic, and the events surrounding it, have changed our reality, and exposed the cracks in our political, economic, and social systems. Before I get to these broken systems, let me go back to my pre-COVID-19 reality for a moment.

I have spent the last twenty years researching, teaching, and advocating to address how inequities in the social determinants of health are root causes for health inequities across ethnic groups in Hawai'i. I have shared that our health and wellbeing are strongly linked to our socioeconomic and educational status, physical environment, social support networks, access to health care, and race/ethnicity. I have shared that the decisions of policymakers and business leaders strongly influence these social determinants of health.

I borrowed catchy one-liners to make my points, such as "It is more about your zip code than your genetic code." Or "It is about what matters to people, not what's the matter with people." Or "The conditions under which we live, play, learn, work, and age affect how well and long we live." I shared these thoughts - notions with robust scientific backing - with policymakers, clinicians, healthcare administrators, other scientists, and the public.

These catchy one-liners did not impress all.

Policymakers, clinicians, and other scientists often asked me-

"Aren't these disparities due to bad genes and lifestyle choices?"

"If they ate better and got more exercise, wouldn't they avoid these health problems?"

"If they comply with medical advice, wouldn't they do better?"

These questions exemplify a myopic view of a bigger, more complex picture surrounding health equity. They also blame the individual-as if people choose to live unhealthy lives and die prematurely. 
When I shared the same ideas about social determinants of health with the public, instead of asking questions, they shared with me their life stories-real examples of how their economic, work, and social circumstances get in the way of them living healthier. They also shared their experiences, good and bad, with medical insurers and the healthcare system. An Aunty struggling to manage her diabetes once told me-

"If I could, I would, but I cannot, 'as why hard."

She was saying that her ability to live a healthier life was not under her direct control. If her life circumstances were better, her health would be better.

The prevailing mindset among many leaders in politics, science, and healthcare stresses the genetic and biological over the social determinants of health. In fairness to my colleagues, many of them do recognize the social determinants of health, but feel ill-equipped to address these issues in their work. Some believe that these issues are too large and complex to change. Even public health funders seem to favor scientific investigations that discover new drugs or genes over those that discover how social conditions influence health, or how innovative community-driven solutions can prevent disease. I felt like a fish swimming against the current.

Enter COVID-19, a disease that spread rapidly around the entire world. A disease that government leaders proclaimed was colorblind and income-blindthat everyone was equally vulnerable. As it turns out, they were wrong. COVID-19 does discriminate-not based on lifestyle choices, but on life circumstances. The social determinants of health (Abrams and Szefler).

We see inequities in the risk of contracting COVID-19, in the severity of symptoms, and in the frequency of hospitalizations and death when infected. Essential workers, who are among the lowest paid in our society, have a greater exposure risk to COVID-19 and of exposing their families and neighbors. These inequities follow ethnic lines and socioeconomic conditions. Pacific Islanders have the most positive COVID-19 cases of all ethnic groups in Hawai' $\mathrm{i}$ (Kaholokula et al.). It is the same in other states, such as California, Oregon, Washington, and Utah, where Pacific Islanders are prevalent.

We are also seeing an uneven distribution of the financial burden and behavioral health problems caused by the COVID-19 containment and mitigation efforts across different populations. Those living under dire socioeconomic conditions before COVID-19 have taken the biggest hits. They are experiencing more severe financial deprivation and drastic increases in depression, interpersonal violence, and substance use during this crisis - problems likely to remain long after the discovery of a COVID-19 vaccine. These vulnerable populations-Native Hawaiians, Pacific Islanders, and Filipinos-are more likely to live in poorer socioeconomic conditions, denser homes and neighborhoods, and to be overrepresented among the homeless, incarcerated, and essential workforce than other ethnic groups. 
COVID-19 has shined a light through the cracks of our systems, spotlighting the social determinants of health for me. It has awakened our understanding that inequities beget inequities, that our systems are actually broken, and that our old values and assumptions are flawed.

How will we emerge from this COVID-19 crisis? Will we maintain status quo, or make profound changes to our political, economic, and social systems? Will we continue to make decisions based on consumption and acquisition, or conservation and cooperation? Will we go back to our overreliance on tourism, or diversify and localize our economic base? Will we invest in our public education system the same way we vigorously have invested in tourism and development? Will we respect Indigenous rights and knowledge and preserve our natural and cultural resources, or will we continue exploiting them?

Here are some ripe ideas for systemic transformation:

- Make public-private investments in our public school system, from pre-primary to tertiary education. There should be no inequities in the value of education between private and publicly administered schools, or all social groups in Hawai' $i$. We also need to invest in our university system to strengthen our workforce and promote innovation. Education strongly impacts our health (Braveman and Gottlieb).

- Provide livable wages, in part through a higher minimum wage. A person should not need to work multiple jobs to make ends meet. States that have moved to higher minimum wages found that people were spending more, which strengthened the overall economy. Also, the more we earn, the longer we live (Neumayer and Plumper).

- Diversify and localize our economic base. As we diversify our economy and move toward lifting up local businesses, innovation, and entrepreneurship, we increase opportunities at home for our young people.

- Make Hawai'i affordable for kamaāina. We have seen an exodus of people due to the cost of living in paradise (Peterkin).

- Invest in those neighborhoods and communities where health promotion makes the most sense. People who live in communities with strong government investment live longer (Neumayer and Plumper).

- Ensure equitable access to educational, financial, and occupational opportunities, regardless of ethnicity or social condition. Tear down the walls of structural racism.

- Use Native Hawaiian values and perspectives to preserve our cultural and natural resources. Our natural resources are finite and fragile. Our cultural resources make us resilient and diverse, and our Native Hawaiian culture makes us exceptional and unified. 
At the time of writing, Hawai' $\mathrm{i}$ had the lowest number of people who contracted COVID-19 and the second-fewest deaths of any state in the US. In that first wave, our value of aloha helped to contain the spread of COVID-19. While people elsewhere were worried about losing their rights due to the physical distancing and mask-wearing requirements, the people of Hawai'i readily complied with these necessary public health measures. We suspended our rights for the collective good because of our aloha for each other and our collective island values. We immediately turned our attention to protecting our 'ohana and kupuna and the homeless and incarcerated. We were able to flatten the curve in that first wave.

Now, Hawai' $i$ is near the top of all states where COVID-19 cases have grown the fastest. We need to once again show our aloha for each other and comply with all COVID-19 containment and mitigation measures.

After this crisis is over, let aloha also be the unifying value of Hawai' $i$ that will be the catalyst for this Hulihia!

\section{Works Cited}

Abrams, Elissa M., and Stanley J. Szefler. "COVID-19 and the Impact of Social Determinants of Health.” Lancet Respiratory Medicine, vol. 8, no. 7, 2020, pp. 659-61.

Braveman, Paula, and Laura Gottlieb. “The Social Determinants of Health: It's Time to Consider the Causes of the Causes." Public Health Reports, vol. 129, suppl. 2, 2014, pp. 19-31.

Kaholokula, Joseph Keawe'aimoku, et al. "COVID-19 Special Column: COVID-19 Hits Native Hawaiian and Pacific Islander Communities the Hardest." Hawai' $i$ Journal of Health \& Social Welfare, vol. 79, no. 5, 2020, pp. 144-46.

Neumayer, Eric, and Thomas Plumper. "Inequalities of Income and Inequalities of Longevity: A Cross-Country Study." American Journal of Public Health, vol. 106, no. 1, 2016, pp. 160-65.

Peterkin, Olivia. "Hawaii Loses Nearly 5,000 Residents Amid Slowest US Population Growth in Decades." Pacific Business News, 31 Dec. 2019.

Joseph Keawe'aimoku Kaholokula, PhD, is Professor and Chair of Native Hawaiian Health, John A. Burns School of Medicine, University of Hawai'i at Mānoa. 